\title{
Telecontrolling pada Kandang Jangkrik Berbasis IoT (Internet of Things)
}

\author{
Mohammad Adib ${ }^{1}$, Lis Diana Mustafa ${ }^{2}$, Nugroho Suharto ${ }^{3}$ \\ 1,3 Program Studi Jaringan Telekomunikasi Digital, \\ Jurusan Teknik Elektro, Politeknik Negeri Malang, Indonesia \\ 2 Program Studi Teknik Telekomunikasi, \\ Jurusan Teknik Elektro, Politeknik Negeri Malang, Indonesia
}

$\underline{\text { 1adib.palu@gmail.com, }{ }^{2} \text { lis.diana@polinema.ac.id, }{ }^{3} \text { nugroho.suharto@polinema.ac.id }}$

\begin{abstract}
Cicadas are a unique type of insect, have a distinctive sound and are active at night, Cicadas are widely cultivated by the community because they can support the community's economy both for pet feed, animal feed mixtures, food additives to cosmetic mixtures. Aspects that need to be considered in the cultivation of Cicadas, namely environmental factors that affect the life and growth of Cicadas daily are from sources of nutrition, temperature and humidity. DHT22 and RTC sensors to measure temperature and humidity in the cricket cage and RTC to detect time. The sensor data input will be processed by ESP32 which is a System on Chip with Wi-Fi and Bluetooth, then detected by Fuzzy Logic to determine the activation output and when the Cicadas are harvested will be sent via the telegram application. The results of the system design for control and monitoring have been successfully implemented in the cricket cage based on temperature, humidity and time. The system can send output notifications and responses in accordance with predetermined conditions with the telegram application and data storage on the website. Testing the accuracy of the sensor gets a fairly accurate presentation of accuracy, that is, on average the percentage accuracy of temperature gets $98 \%$ and at humidity it gets a value of $97 \%$, and Testing the results of the percentage of accuracy on the system and fuzzy simulation using telegram and matlab applications gets a percentage value $31.66 \%$ accuracy.
\end{abstract}

Keywords - Cicadas, DHT22, RTC, Fuzzy Logic, Internet of Things

\begin{abstract}
Abstrak - Jangkrik adalah jenis serangga yang unik, memiliki suara khas dan aktif pada malam hari, jangkrik banyak dibudidayakan oleh masyarakat karena dapat menjadi penompang perekonomian masyarakat baik untuk pakan binatang piaraan,campuran pakan ternak,bahan tambahan pangan hingga campuran kosmetik. Aspek yang perlu di perhatikan dalam pembudidayaan jangkrik yaitu faktor lingkungan yang mempengaruhi hidup dan pertumbuhan jangkrik sehari-hari adalah dari sumber nutrisi,suhu dan kelembapan.Maka dari itu dibuatlah alat "Telecontrolling Pada Kandang Jangkrik Berbasis IoT (Internet of Things)" Alat ini menggunakan sensor DHT22 dan RTC untuk mengukur suhu dan kelembapan didalam kandang jangkrik dan RTC untuk mendeteksi waktu. Input data sensor akan diolah oleh ESP32 yang merupakan System on Chip dengan Wi-Fi dan Bluetooth, kemudian di deteksi oleh Fuzzy Logic untuk menentukan output pengaktifannya dan kapan ternak jangkrik waktunya panen akan dikirim melalui aplikasi telegram.Hasil perancangan sistem untuk kontrol dan monitoring berhasil diterapkan pada kandang jangkrik dengan berdasarkan suhu, kelembapan dan waktu. Sistem dapat mengirimkan notifikasi output dan respon sesuai dengan kondisi yang telah ditentukan dengan aplikasi telegram dan penyimpanan data pada website. Pengujian akurasi sensor mendapatkan hasil presentasi ketelitian yang cukup akurat, yaitu pada rata-rata presentase akurasi suhu mendapat milai $98 \%$ dan pada kelembapan mendapatkan nilai 97\%, dan Pengujian hasil presentase akurasi pada sistem dan simulasi fuzzy dengan menggunakan aplikasi telegram dan matlab mendapatkan nilai presentase akurasi $31,66 \%$.
\end{abstract}

Kata kunci- Jangkrik, DHT22, RTC, Fuzzy Logic, Internet of Things

\section{PENDAHULUAN}

Jangkrik merupakan salah satu pilihan yang tepat untuk dikembangbiakan hal ini dikarenakan jangkrik memiliki kandungan protein yang sangat tinggi. Di Indonesia sendiri dengan iklim yang tropis merupakan wilayah yang paling pas untuk melakukan budidaya jangkrik[1]. Ada lebih dari 100 jenis jangkrik yang terdapat di Indonesia.Jenis jangkrik yang banyak dibudidayakan ini adalah Gryllus Mitratus dan Gryllus Testascus,banyak digunakan untuk pakan ikan dan burung. Kedua jenis jangkrik tersebut dapat dibedakan dari bentuk tubuhnya, dimana Gryllus Mitratus wipositornya lebih pendek dan pada Gryllus Testaceus memiliki garus pada pinggir sayap punggung, serta penampilannya yang tenang.[2]
Prospek usaha ternak jangkrik sebenarnya cukup menjanjikan dengan jangka waktu pembudidayaan yang cukup singkat yaitu kurang lebih 30 hari. Faktor kematian jangkrik pada umur 15-20 hari keatas berhubungan erat dengan suhu dan kelembapan dalam kandang jangkrik[1].Pembudidayaan jangkrik memerlukan kondisi lingkungan yang sesuai. Aspek yang perlu di perhatikan dalam budidaya jangkrik, salah satunya adalah persiapan media penetasan dan pertumbuhan karena media tersebut penting demi keberlangsungan regenerasi.Faktor lingkungan yang mempengaruhi hidup dan pertumbuhan jangkrik adalah dari sumber nutrisi,suhu dan kelembapan.Di alam, jangkrik banyak dijumpai pada musim hujan, dan jarang ditemukan pada musim kemarau. Di Indonesia, jangkrik umumnya hidup baik di daerah yang 
bersuhu antara $20^{\circ} \mathrm{C}-32^{\circ} \mathrm{C}$ dengan kelembapan berkisar $65 \%$ $80 \%[3]$.

Pada skripsi ini akan dirancang sebuah sistem yang menggunakan inputan dari sensor DHT22. DHT22 diklaim memiliki kualitas pambacaan yang baik, dinilai dari respon proses akuisisi data yang cepat dan ukurannya yg minimalis, serta dengan harga yang relatif murah jika dibandingkan dengan alat thermohygromoeter [4] dan RTC dapat menyimpan data waktu secara real time [5]-[7] melalui proses hitung waktu dilakukan output datanya langsung disimpan atau bisa dikirim ke device lain melalui sistem I2C [8]-[11], untuk membaca waktu dari kandang agar bisa mengetahui waktu panen jangkrik. Data dari inputannya akan diolah oleh ESP32 yang berupa System on Chip dengan Wi-Fi dan Bluetooth [12][16]. Kemudian dideteksi oleh Fuzzy Logic untuk menentukan nilai optimal [7] output yang berupa penyalaan bohlam lampu atau penyalaan mist maker sehingga status suhu dan kelembapan kandang jangkrik tetap stabil serta membaca RTC untuk mengirim data waktu dari kandang jangkrik. Dari sistem ini juga bisa mengontrol output melalui browser dan monitoring status kandang jangkrik melalui browser dan notifikasi telegram [15]. Tujuannya agar peternak tidak perlu mengecek langsung ke kandang jangkrik. Diharapkan dengan adanya sistem ini dapat membantu peternak jangkrik dalam melakukan kontrol dan monitoring suhu dan kelembapan serta waktu panen pada kandang jangkrik dengan jarak jauh serta mengenalkan teknologi Internet of Things (IoT) di kalangan peternak jangkrik.

\section{METODE}

\section{A. Perancangan Sistem}

Secara sistematis cara kerja alat yang dijalankan sistem dijadikan dalam bentuk Diagram Blok ditunjukkan Gambar 1 dibawah ini.

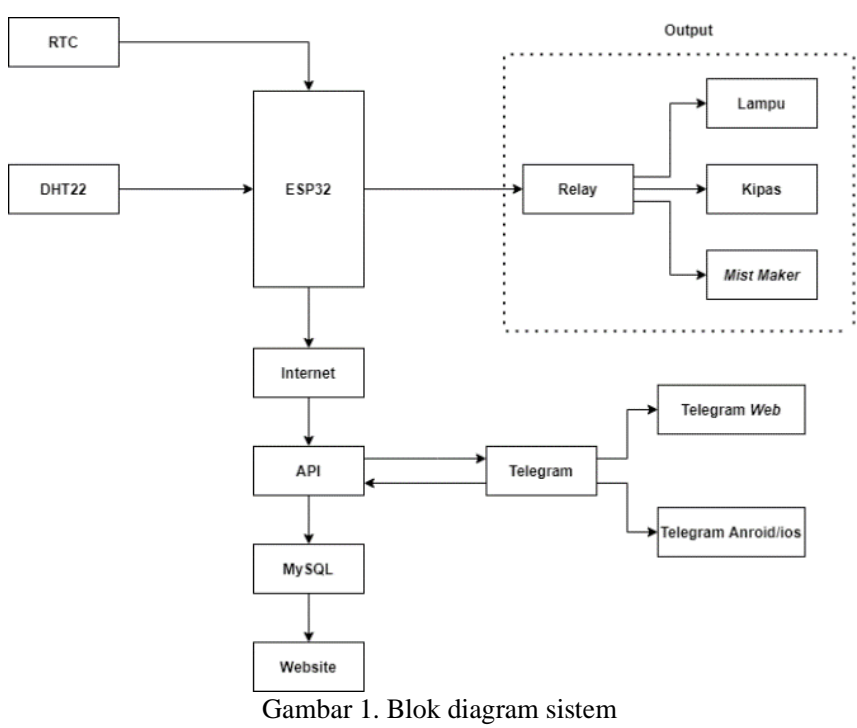

Dari Gambar 1, terdapat diagram blok tahapan penelitian yang dijelaskan untuk masing-masing blok meliputi. Alur dari dari diagram blok meliputi pengumpulan data sensor suhu dan kelembapan (DHT 22) dan pendeteksi waktu (RTC) yang terhubung dengan ESP32.ESP32 mengolah data yang diterima menggunakan metode Fuzzy Logic setelah itu hasil data yang sudah diolah dikirim ke relay untuk menyalakan atau mematikan output yaitu lampu, kipas dan mist maker. Setelah dikirim ke relay data yang telah diolah juga disimpan di database MySQL melalui API yang harus terhubung ke internet. Setelah itu data yang telah diolah sebelumnya bisa dilihat dari website dan Telegram akan mendapat notifikasi apabila output dinyalakan.

Sistem yang akan dibuat bertujuan untuk melakukan deteksi suhu kelembapan dan waktu yang diperlukan pada kandang jangkrik, apabila suhu dan kelembapan tidak sesuai maka output yang disediakan akan menyala agar kondisi suhu dan kelembapannya sesuai dengan himpunan fuzzy yang telah diatur serta mendapat pesan notifikasi jika jangkrik sudah memasuki waktu makan atau panen. Hal ini dirancang agar jangkrik dapat tumbuh dengan maksimal.berikut merupakan gambaran dari sistem secara umum.

Berikut arsitektur sistem perancangan sistem Telecontrolling pada Kandang Jangkrik Berbasis Internet of Things:

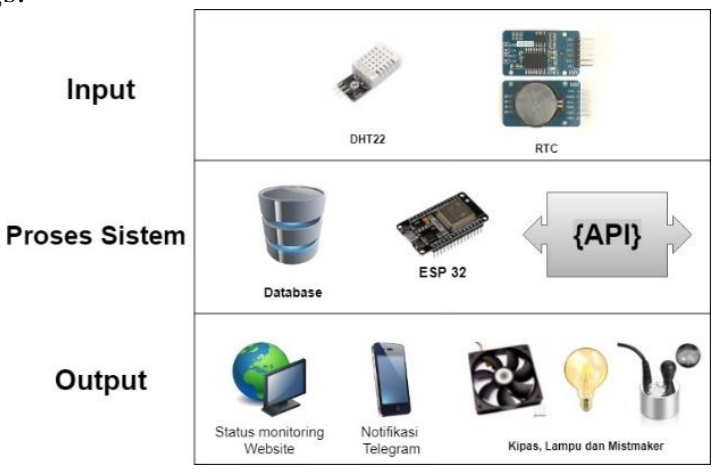

Gambar 2. Asitektur sistem

Adapun penentuan prosedur yang digunakan penelitian untuk judul "Telecontrolling Pada Kandang Jangkrik Berbasis Internet of Things" ditunjukkan pada Gambar 3.

Pada Gambar 3 tersebut, alat tersebut digunakan pada kandang jangkri yang dioperator oleh petani. Pada Diagram Activity, jika ada perintah untuk menyalakan lampu, atau mist maker dari petani maka perintah akan dieksekusi. Jika tidak maka sistem akan membaca sensor suhu dan kelembapan serta sensor RTC. Setelah itu akan dilanjukan ke proses pengunaan Fuzzy seperti Fuzzyfikasi, lalu dilanjutkan dengan subproses implikasi. Setelah itu output yang sudah ada dieksekusi dengan adanya penyalaan alat-alat.Kemudian hasil outputnya akan diterima melalui notifikasi aplikasi Telegram dari peternak. Setelah notifikasi dikirimkan output akan disimpan di database. Kemudian data yang telah disimpan di database akan ditampilkan pada website agar peternak bisa dipermudah dalam proses monitoring. Jika sistem telah diaktifkan maka akan kembali ke pembacaan sensor. Jika sistem tidak diaktifkan maka sistem akan kembali mati.

Perencanaan dan pengumpulan data akan diambil dari data inputan sensor suhu dan kelembapan.Setelah itu data inputan akan terkumpul dan dapat dianalisa dengan alur dan aturan yg 
sesuai berdasarkan salah satu metode dari fuzzy logic yaitu fuzzy sugeno.

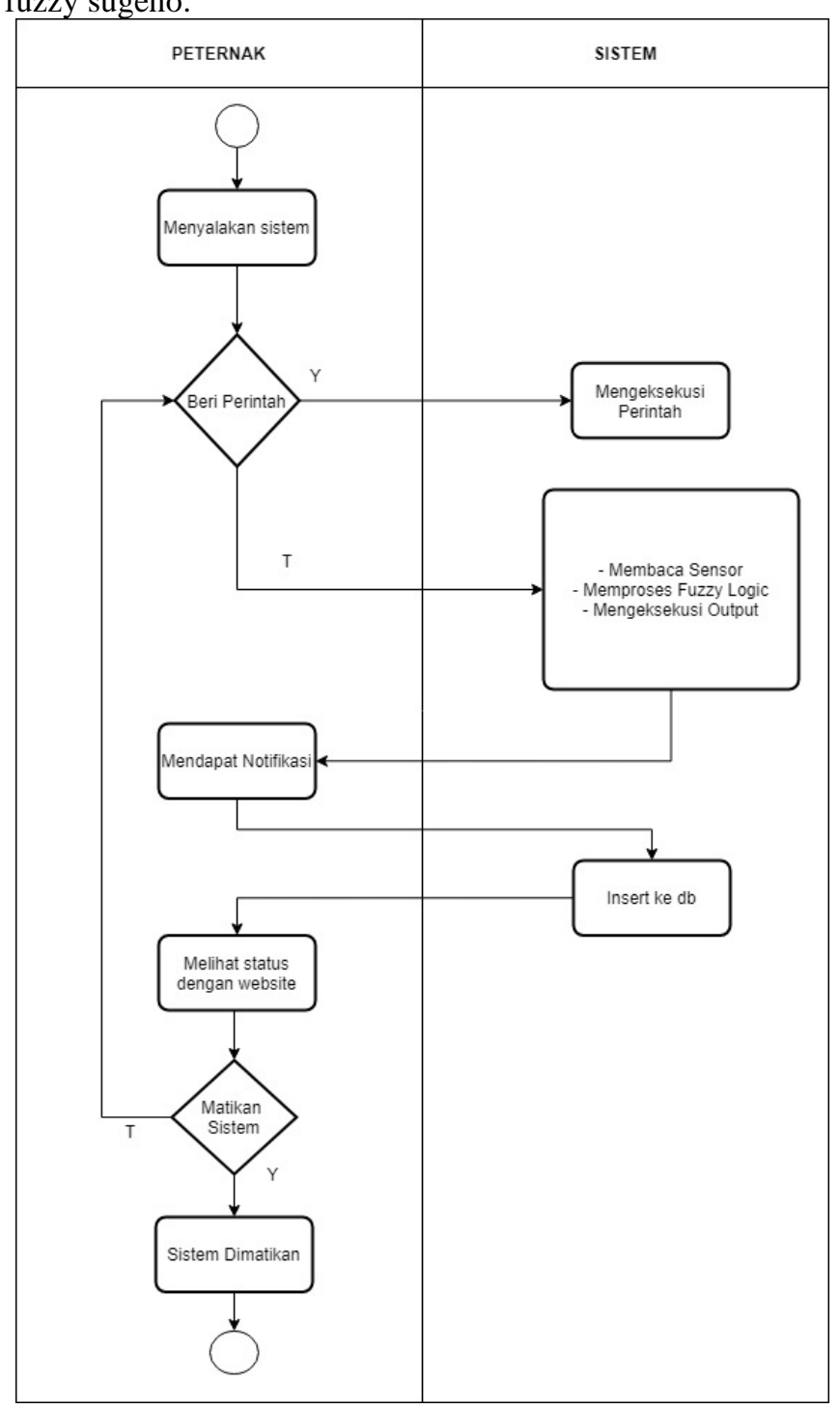

Gambar 3. Diagram alir prosedur

Pada Gambar 4 dan Gambar 5 menunjukan rancangan menggunakan himpunan keaggotaan dari dua inputan yaitu suhu dan kelembapan. Parameter dari suhu yaitu dingin (028C), hangat (25-31C) dan panas $(>=31 \mathrm{C})$ sedangkan dari kelembapan yaitu kering (0-70\%), lembap (60-80\%) dan basah $(>=80 \%)$.

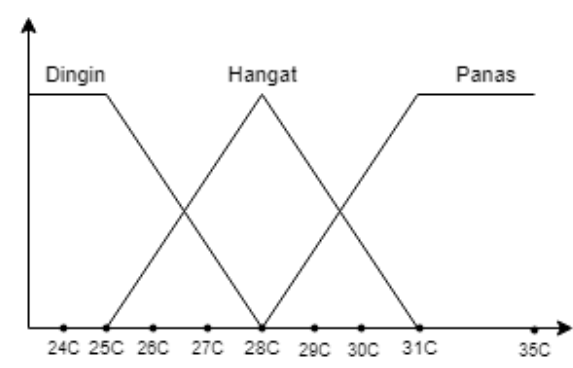

Gambar 4 himpunan keanggotaan suhu

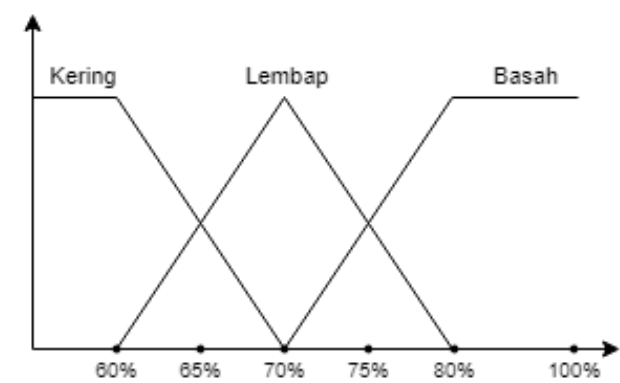

Gambar 5 Himpunan keanggotaan kelembapan

\section{B. Perancangan Mekanik}

Perencanaan ini menjadi bagian pertama dari pembahasan perangkat yang berguna untuk memudahkan pembuatan alat di tahap berikutnya, pada perencanaan desain akan ditampilkan dalam bentuk kubus kendang, ditunjukkan Gambar 6 dan 7.

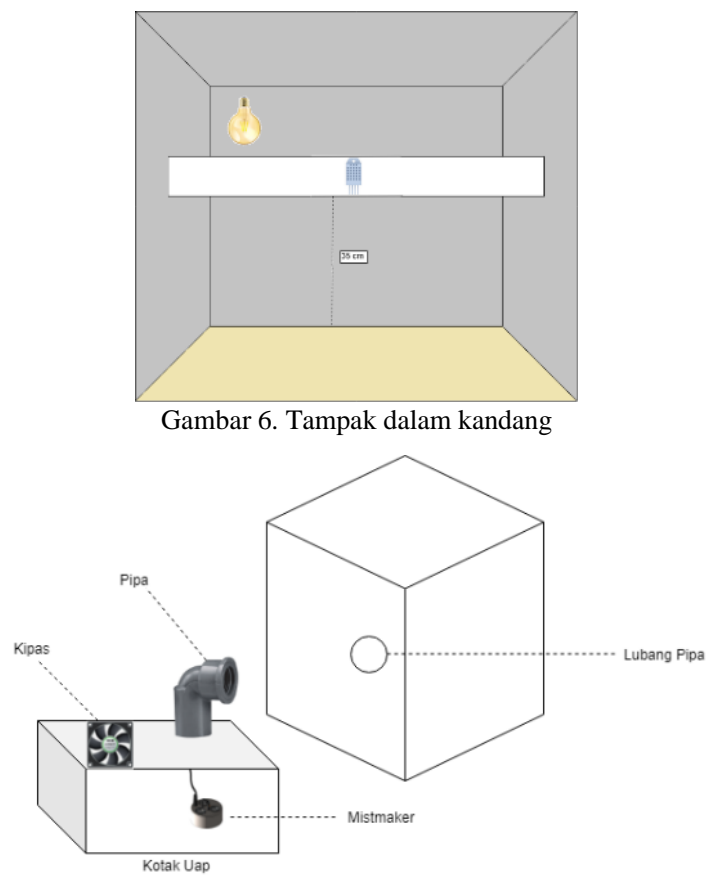

Gambar 7. Tampak luar kandang

Pada gambar 6 dalam kandang dia atas, terdapat sensor DHT22 yang terpasang ditengah kayu yang berada $55 \mathrm{~cm}$ diatas lantai kandang, serta output seperti bohlam untuk menghangatkan kandang dan lubang pipa untuk keluarnya uap dan angin kipas. Sedangkan dari tampak luar kandang terdapat kotak yang berisi mistmaker dan kipas yang tersambung dengan pipa ke dalam kandang jangkrik, fungsi dari kotak untuk menghasilkan uap air dan angin dari kipas masuk ke dalam kandang jangkrik melalui pipa yang terlah disambungkan, dilihat di Gambar 7.

\section{Perancangan Elektrik}

Perencanaan elektrik adalah tahap bagaimana komponen elektronik bekerja. Dalam tahap ini akan ditunjukkan cara kerja tiap komponen. 


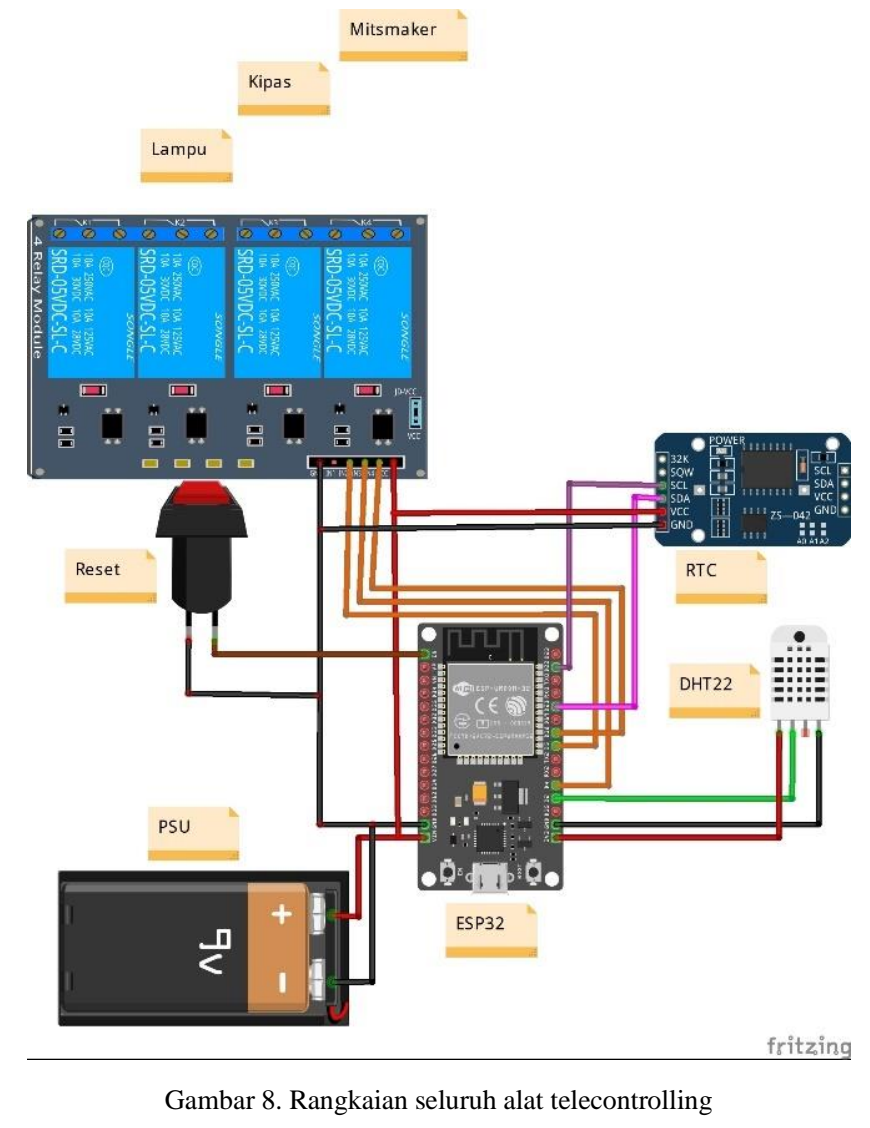

Pada gambar 8 menampilkan gambar rangkaian keseluruhan alat telecontrolling pada kandang jangkrik berbasis Internet of Things (IoT).

\section{Perancangan Software}

Agar perencanaan alat dapat digunakan dan berjalan sesuai dengan yang direncanakan, maka dibutuhkan suatu perencanaan software. Tujuan dari perencanaan ini adalah untuk merancang software aplikasi yang akan digunakan untuk mengoperasikan sistem. Dari Software ini nantinya akan digunakan oleh para peternak jangkrik. Berikut perencanaan yang akan dipakai pada alat, ditunjukkan Gambar 9.

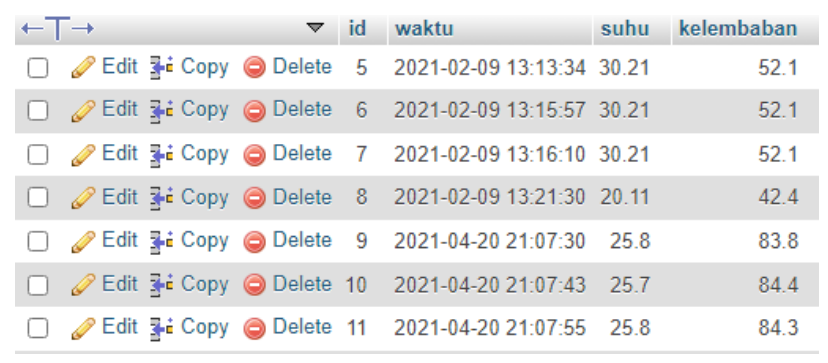

Gambar 9. Struktur database MySQL

Untuk mengkontrol dan memonitoring pada alat ini dengan menggunakan aplikasi telegram, pada aplikasi telegram tersedia fitur bot yang dapat kita sambungkan ke arduino sehingga dapat memudahkan para peternak jangkrik untuk beternak dengan menggunakan aplikasi.

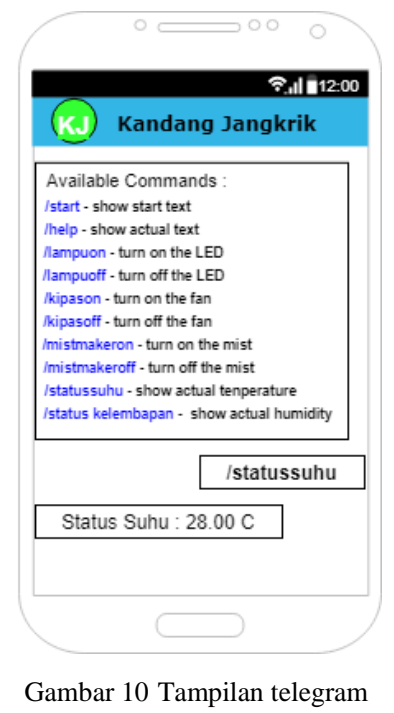

\section{HASIL DAN PEMBAHASAN}

\section{A. Hasil Perancangan Sistem}

Hasil perencanaan sistem dibagi menjadi dua hasil, yaitu hasil perencanaan pada hardware dan hasil perencanaan pada software.

Pada hasil perencanaan hardware pada penelitian ini terdiri dari kandang utama jangkrik yang terbuat dari kayu dan beberapa lapis tripleks, dibagian atas kandang diberikan jaringjaring agar sirkulasi udara dapat masuk kedalam kandang dan jangkrik tidak dapat keluar, sedangkan di salah satu bagian sisi kandang terdapat dua lubang untuk masuknya pipa yang tersambung dengan kotak uap dan satu lubang lagi untuk masuknya sensor DHT22. DHT22 terhubung dengan box elektronik yang didalam boxnya sudah terdapat komponen dan rangkaian elektronik terdiri dari ESP32 sebagai mikrokontroller utama, komponen RTC yang juga tersambung ke mikrokontroller agar dapat menjadi pengingat waktu dan tanggal.

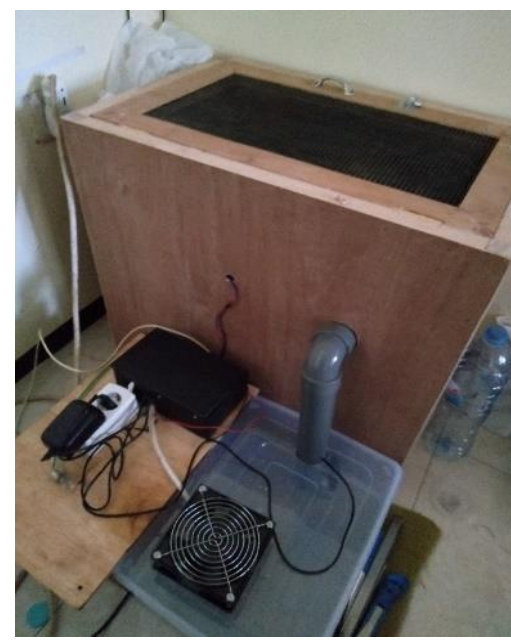

Gambar 9. Implementasi keseluruhan alat 


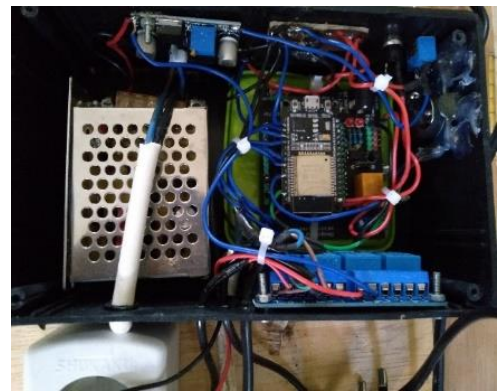

Gambar 10 Komponen pada box elektronik

Pada gambar 9 tampak komponen-komponen yang telah siap untuk dipakai dengan komponen yang berupa box elektronik yang menyambungkan input dan output ke kandang jangkrik dan juga ke kotak uap, lalu dari kotak uap tersambung dengan pipa untuk masuk ke kandang jangkrik.

Selain itu juga menampilkan komponen-komponen utama yang terpasang pada box elektronik, komponen tersebut seperti mikrokontroller ESP32 yang berfungsi sebagai pengontrol rangkaian elektronik, modul RTC yang berfungsi sebagai input pengatur waktu pada kandang jangkrik, komponen Relay yang berfungsi sebagai pengatur aktifnya output yang akan terpakai di setiap kondisi kandang, dan power supply $5 \mathrm{~V}$ yang berfungsi untuk menyalurkan daya ke setiap komponen.

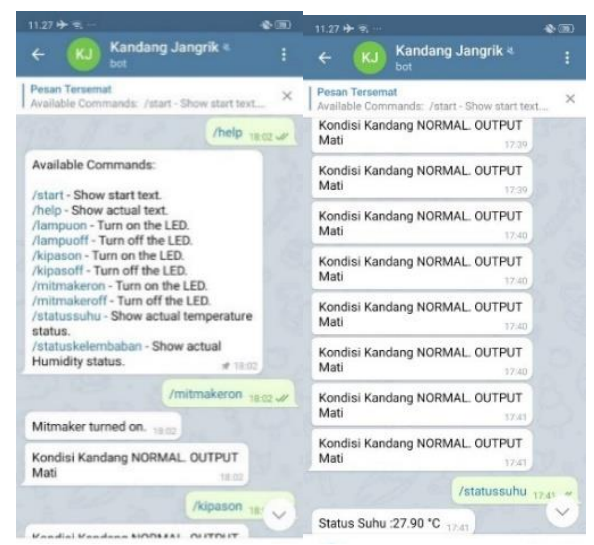

Gambar 10. Implementasi pada Telegram

Pada gambar 10 menunjukan gambar tampilan menu perintah pada telegram, dari beberapa menu perintah yang tertampil, 6 perintah awal merupakan untuk mengaktifkan output secara manual (lampu, kipas dan mistmaker). Sedangkan pada perintah terakhir yaitu untuk mengecek status suhu dan kelembapan dari kandang jangkrik. Serta gambar tampilan notifikasi pada telegram sesuai dengan perencanaan pada bab 3, pada notifikasi berupa kondisi kandang dan output sesuai aturan fuzzy yang telah diatur.

TABEL I

DATA SUHU DAN KELEMBABAN KANDANG JANGKRIK

\begin{tabular}{cccc}
\hline No & Waktu & Suhu $\left({ }^{\circ} \mathbf{C}\right)$ & Kelembaban $(\%)$ \\
\hline 1 & $2021-07-1606: 31: 44$ & 22 & 73.1 \\
2 & $2021-07-1606: 31: 59$ & 22.1 & 74.1 \\
3 & $2021-07-1606: 32: 25$ & 22.1 & 73.7 \\
4 & $2021-07-1606: 32: 39$ & 22.1 & 73.8 \\
5 & $2021-07-1606: 32: 54$ & 22 & 73.6 \\
\hline
\end{tabular}

\begin{tabular}{cccc}
\hline No & Waktu & Suhu $\left({ }^{\circ} \mathbf{C}\right)$ & Kelembaban $(\%)$ \\
\hline 6 & $2021-07-1606: 33: 24$ & 22 & 73.8 \\
7 & $2021-07-1606: 33: 39$ & 22 & 73.8 \\
8 & $2021-07-1606: 33: 53$ & 22 & 73.4 \\
9 & $2021-07-1606: 34: 06$ & 22.1 & 73.3 \\
10 & $2021-07-1606: 34: 18$ & 22 & 73.1 \\
11 & $2021-07-1606: 34: 31$ & 22 & 74 \\
12 & $2021-07-1606: 34: 44$ & 22.1 & 73.6 \\
13 & $2021-07-1606: 34: 56$ & 22 & 73.1 \\
14 & $2021-07-1606: 35: 17$ & 22 & 73.1 \\
15 & $2021-07-1606: 35: 26$ & 22 & 73.1 \\
16 & $2021-07-1606: 35: 39$ & 22 & 73.1 \\
\hline
\end{tabular}

Pada Gambar 11 menampilkan respon dari input modul RTC yang menampilkan waktu realtime dari kandang jangkrik, serta repon dari input sensor DHT22 yang manampilkan suhu dan kelembapan status kandang jangkrik.

\section{B. Pengujian Suhu}

Pengujian akurasi sensor DHT22 dilakukan untuk memastikan jika sensor DHT22 dapat mendeteksi nilai suhu dan kelembapan pada ruangan yang akurat. Dalam pengujian ini output dari nilai sensor DHT22 dikirimkan ke database MySQL untuk disimpan datanya lalu nilai tersebut dapat dilihat pada aplikasi telegram. Hasil pengujian akurasi sensor DHT22 dengan Hygrometter didapatkan data sebagai berikut.

Rumus prosentase error:

$$
\begin{aligned}
\text { Error } & =\frac{(\text { Nilai Terbaca }- \text { Nilai Sebenarnya })}{\text { Nilai Terbaca }} \times 100 \% \\
& =\frac{(\text { Nilai DHT } 22-\text { Nilai HTC }-1)}{\text { Nilai DHT } 22} \times 100 \% \ldots . .
\end{aligned}
$$

Perhitungan rata-rata error pada data suhu dan kelembapan:

$$
\text { Rata }- \text { rata error }=\frac{\text { Jumlah Error Keseluruhan Data }}{\text { Jumlah Data }} .
$$

Berdasarkan tabel 1 sensor DHT22 digunakan untuk menginput data suhu di dalam kandang jangkrik dan dibandingkan dengan alat ukur manual yaitu Hygrometer dan menapatkan hasil selisih dan nilai error yang cukup akurat.

TABEL II

HASIL PENGUJIAN SUHU SENSOR DHT22 DENGAN HYGROMETER

\begin{tabular}{ccccc}
\hline Waktu (WIB) & $\begin{array}{c}\text { Hygrometer } \\
\left({ }^{\circ} \mathbf{C}\right)\end{array}$ & $\begin{array}{c}\text { Sensor } \\
\left({ }^{\circ} \mathbf{C}\right)\end{array}$ & Selisih & Nilai Error \\
\hline 06.40 WIB & 20 & 19.5 & 0.5 & $2 \%$ \\
06.42 WIB & 20.6 & 20.2 & 0.4 & $1 \%$ \\
06.44 WIB & 21.4 & 21.1 & 0.3 & $1 \%$ \\
06.49 WIB & 22.6 & 22 & 0.6 & $2 \%$ \\
19.15 WIB & 27 & 26.5 & 0.5 & $1 \%$ \\
15.13 WIB & 27.5 & 27.3 & 0.2 & $0 \%$ \\
14.53 WIB & 29 & 28.4 & 0.6 & $2 \%$ \\
\hline
\end{tabular}

TABEL III

HASIL PENGUJIAN SUHU SENSOR DHT22 DENGAN HYGROMETER

\begin{tabular}{ccccc}
\hline Waktu & $\begin{array}{c}\text { Hygrometer } \\
(\boldsymbol{\%})\end{array}$ & $\begin{array}{c}\text { Sensor } \\
(\boldsymbol{\%})\end{array}$ & Selisih & $\begin{array}{c}\text { Nilai } \\
\text { Error }\end{array}$ \\
\hline 06.36 WIB & 63 & 62.8 & 0.2 & $3 \%$ \\
06.39 WIB & 72 & 70.4 & 1.6 & $2 \%$ \\
06.47 WIB & 78 & 75.7 & 2.3 & $2 \%$ \\
19.59 WIB & 80 & 77.6 & 2.4 & $3 \%$ \\
19.15 WIB & 83 & 80 & 3 & $3 \%$ \\
15.13 WIB & 84 & 82.8 & 1.2 & $1 \%$ \\
06.40 WIB & 88 & 84.6 & 3.4 & $3 \%$ \\
\hline
\end{tabular}


Dari Tabel II dan Tabel III, sensor DHT22 digunakan untuk menginput data kelembapan di dalam kandang jangkrik dan dibandingkan dengan alat ukur manual yaitu Hygrometer dan mendapatkan hasil selisih dan nilai error yang cukup akurat:

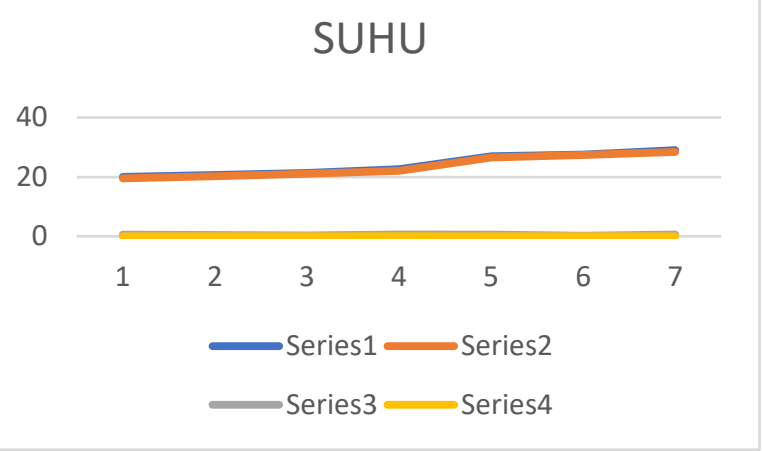

Gambar 11. Grafik perbandingan pengujian suhu menggunakan DHT22 dan hygrometer

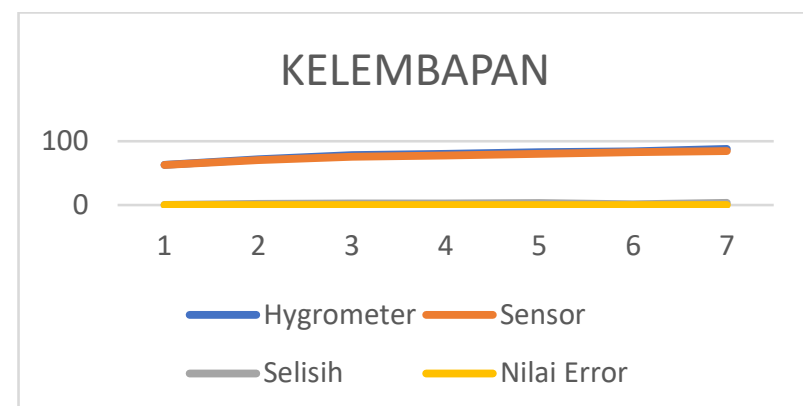

Gambar 12. Grafik perbandingan pengujian kelembapan menggunakan DHT22 dan hygrometer

\section{Implementasi Perhitungan Fuzzy Sugeno}

Proses perhitungan dengan menggunakan metode fuzzy sugeno yaitu untuk mengambil data dari suhu dan kelambapan yang ada pada prototype kandang jangkrik., berikut contoh pengururaian alur perhitungan dengan metode fuzzy sugeno dengan asumsi suhu $30 \mathrm{oC}$ dan kelembapan $70 \%$.

Fuzzifikasi adalah proses pengelompokan data yang bersifat tegas kedalam himpunan fuzzy. Pada penelitian ini proses fuzzifikasi memiliki himpunan keanggotaan dari dua inputan yaitu inputan dari suhu dan kelembapan. Karena dari dua inputan inilah yang mempengaruhi perkembangan dan pertumbuhan dari jangkrik.

TABEL IV

HIMPUNAN KEANGGOTAAN SUHU

\begin{tabular}{cc}
\hline Himpunan Keanggotaan & Suhu \\
\hline Dingin & $0-28 \mathrm{C}$ \\
Hangat & $25 \mathrm{C}-31 \mathrm{C}$ \\
Panas & $>=31 \mathrm{C}$ \\
\hline
\end{tabular}

TABEL V

HIMPUNAN KEANGGOTAAN KELEMBAPAN

\begin{tabular}{cc}
\hline Himpunan Keanggotaan & Suhu \\
\hline Kering & $0 \%-70 \%$ \\
Lembap & $60 \%-80 \%$ \\
Basah & $>=80 \%$ \\
\hline
\end{tabular}

Berdasarkan tabel 3 dan tabel 4 Himpunan keanggotaan suhu memiliki tiga himpunan yaitu dingin, hangat dan panas.Dan pada Himpunan keanggotaan kelembapan memiliki tiga himpunan yaitu kering,lembap dan basah.

Untuk melakukan penegasann akan menghasilkan nilai tegas, digunakan rumus dengan mencari nilai rata-rata (Weight Average) sebabagai berikut:

$$
W A=\frac{a_{1} z_{1}+a_{2} z_{2}+a_{3} z_{3}+\ldots a_{i} z_{i}}{a_{1}+a_{2}+a_{3}+\ldots i}
$$

Keterangan :

$a i$ : adalah $\alpha$ - predikat ke $-\mathrm{i}$.

$z i$ : adalah konsekuensi ke $-\mathrm{i}$

\section{Implementasi Fuzzy Sugeno pada Matlab}

Pada bagian implementasi dengan menggunakan aplikasi matlab dipergunakan untuk mensimulasikan himpunan anggota yang akan digunakan, untuk himpunan tersebut ada dua, yaitu himpunan suhu dan kelembapan berikut adalah simulasi fuzzy sugeno dengan menggunakan aplikasi matlab.

Pada Gambar 13 menampilkan fungsi simulasi dari himpunan suhu, untuk variabel rangenya diisi nol dan lima puluh (100) agar nilai input bisa diisi hingga nilai seratus. Sedangkan untuk parameternya kita isikan sesuai himpunan yang telah ditentukan berdasarkan keanggotaannya masingmasing.

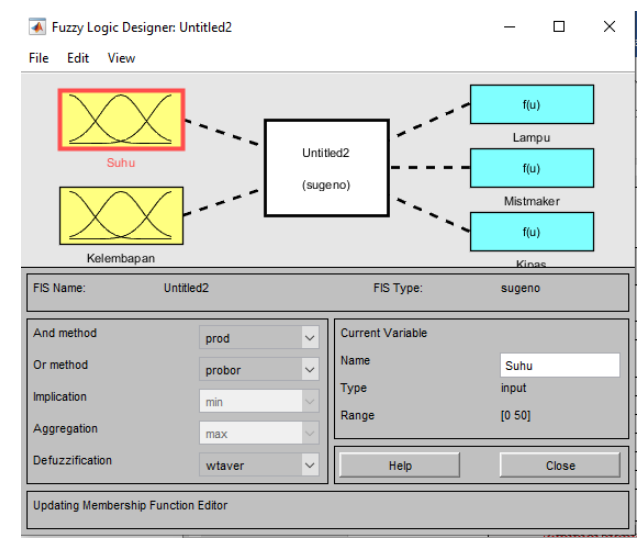

Gambar 13. Rangkaian fuzzy sugeno

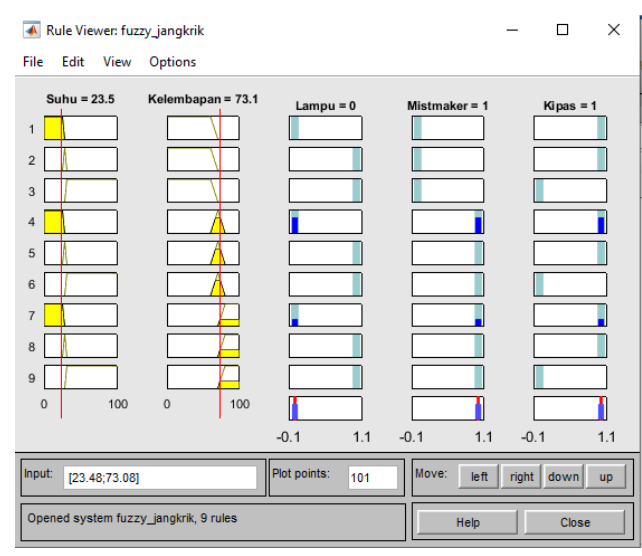

Gambar 14. Simulasi fuzzy sugeno 
Pada gambar 14. menampilkan hasil dari simulasi fuzzy sugeno menggunakan matlab, dari nilai input suhu kelembapan sedemikian maka output yang aktif hanya lampu sedangkan mistmaker dan kipas berstatus mati.

\section{E. Hasil Pengujian Sistem}

Pada pengujian sistem, penerapan input disesuaikan dengan perencanaan yaitu dengan menggunakan komponen sensor DHT22 dan RTC serta pada penerapan output juga telah disesuaikan dengan perencanaan yaitu menggunakan lampu, kipas dan mistmaker. Pengujian hasil output juga melihat respon sistem yang dibuat dengan beberapa simulasi seperti kondisi normal, dingin, panas, kering, kering panas dan kering dingin dengan mengubah nilai variabel yang ada pada mikrokontroller. Berikut hasil pengujian output yang dijasikan dengan bentuk gambar pada tabel:

TABEL VI

PENGUJIAN KONDISI

\begin{tabular}{cl}
$\begin{array}{c}\text { Hasil yang } \\
\text { diharapkan }\end{array}$ & $\begin{array}{l}\text { Dapat melakukan input dan membaca respon dari } \\
\text { sensor DHT22 ke ESP32 }\end{array}$ \\
\hline $\begin{array}{c}\text { 19:36:3 } \\
\text { Hasil Pengujian } \\
\text { Arduino }\end{array}$ & $\begin{array}{l}\text { Suhu }=26.60 \\
\text { Kelembaban }=77.80\end{array}$ \\
\hline $\begin{array}{c}\text { Hasil Pengujian } \\
\text { Telegram }\end{array}$ & Status Suhu :26.60 ${ }^{\circ} \mathrm{C}_{20: 36}$ \\
& $\begin{array}{l}\text { Kondisi Kandang NORMAL. OUTPUT } \\
\text { Mati }\end{array}$ \\
\hline Keterangan & [v] Sesuai \\
\hline
\end{tabular}

Pada Tabel VI menampilkan kondisi normal merupakan kondisi dimana suhu dan kelembapan dari kandang terdeteksi normal. Ketika respon dari sensor terdeteksi normal maka otomatis output akan mati. Berikut tabel pengujian kondisi dari status kondisi normal:

\section{F. Hasil Analisis Quality of Service (QoS)}

Pengujian Quality of Service (QoS) bertujuan untuk mengetahui mengenai kualitas jaringan untuk mendefinisikan sistem dalam pengukuran beberapa parameter QoS yaitu Throughput, Packet Loss, Delay dan Jitter.
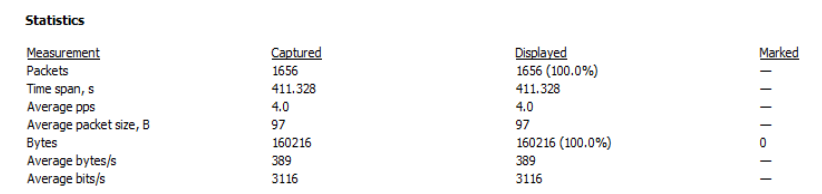

Gambar 15. Tampilan statistik pada wireshark

1) Pengujian Throughput:Throughput merupakan jumlah total kedatangan paket sukses yang diamati selama interval tertentu dibagi oleh durasi interval waktu tersebut.
Throughput merupakan kemampuan suatu jaringan dalam mentransfer data efektif yang diukur dalam bps(byte/s).

$$
\begin{aligned}
\text { Throughput } & =\frac{\text { Paket Data Diterima }}{\text { Lama Pengamatan }}=\frac{160216 \text { Bytes }}{411.328 \mathrm{~s}} \\
& =389 \text { Bytes } / \mathrm{s}
\end{aligned}
$$

Dari hasil perhitungan didapatkan nilai throughput sebesar 389Bytes/s. Menurut standarisasi TIPHON [4] menggunakan satuan Kbps, sehingga 389Bytes/s x 8bit $=3.112 \mathrm{bps}=$ 3,112Kbps.Kecepatan pengiriman data pada wireshark menggunakan satuan Byte/s, sedangkan menurut standarisasi TIPHON menggunakan satuan Kbps sehingga hasil perlu diubah menjadi satuan standar TIPHON yaitu Kbps. Menurut hasil perhitungan didapatkan hasil sebesar 3,112Kbps dimana menurut standarisasi TIPHON nilai tersebut termasuk indeks yang buruk[6]. Hal ini disebabkan data yang dikirim kecil sehingga memengaruhi nilai throughput.

2) Pengujian Packet Loss: Packet loss merupakan suatu kegagalan transmisi paket dalam mencapai tujuannya. Kegagalan tersebut bisa disebabkan oleh beberapa kemungkinan seperti overload traffic dalam jaringan, tabrakan dalam jaringan, dan kegagalan pada sisi penerima.

$$
\begin{aligned}
\text { Packet Loss }= & \frac{(\text { Paket data dikirim }- \text { Paket data diterima }) \times 100 \%}{\text { Paket data dikirim }} \\
& =\frac{(1656-1656) \times 100 \%}{1656}=0 \%
\end{aligned}
$$

Dari hasil perhitungan yang didapatkan nilai packet loss adalah $0 \%$. Sumber dari TIPHON apabila nilai packet loss $0 \%$ maka termasuk kedalam indeks kategori sangat bagus[6]. Hal ini disebabkan karena data yang dikirim dapat diterima dengan baik karena tidak adanya gangguan koneksi.

3) Pengujian Delay: Delay merupakan waktu tunda suatu data yang diakibatkan oleh proses transmisi dari titik asal menuju tujuannya [7]. Delay dipengaruhi oleh jarak, media fisik, congesti maupun proses yang memerlukan waktu cukup lama.

$$
\begin{aligned}
& \text { Delay per paket }=(\text { Waktu kedua }- \text { Waktu pertama }) \\
& =(23.013709000 s-23.013703000 s) \\
& =0,006000 \mathrm{~s} \\
& \text { Total Delay }=\text { jumlah seluruh delay paket } \\
& =67,57906 \mathrm{~s} \\
& \text { Rata }- \text { rata delay }=\frac{\text { jumlah total delay }}{\text { paket yang diterima }} \\
& =411,327 \mathrm{~s} / 1656 \\
& =248,38 \mathrm{~ms}
\end{aligned}
$$

Hasil perhitungan delay yang didapatkan dari nilai rata-rata delay sebesar 248,38ms. Menurut standard TIPHON nilai tersebut termasuk kategori bagus karena nilai termasuk di indeks 150-300 ms. Hal ini disebabkan karena waktu yang diperlukan suatu paket data untuk menempuh jarak dari asal ke tujuan dapat diterima dengan bagus[6].

4) Pengujian Jitter: Jitter merupakan variasi dari delay antar paket yang terjadi pada jaringan. Apabila variasi delay dalam transmisi terlalu lebar, maka akan memengaruhi kualitas data yang ditransmisikan. Besarnya nilai jitter akan sangat 
dipengaruhi oleh variasi beban trafik dan besarnya tabrakan antar paket yang ada dalam jaringan.

$$
\begin{aligned}
\text { Rata - rata Jitter } \quad= & \frac{\text { Total Jumlah Delay }}{\text { Paket yang diterima }} \\
= & \frac{\text { Total Jumlah Jitter }}{\text { Paket yang diterima }} \\
\text { Jitter }= & \frac{\text { Total Variasi Delay }}{\text { Total Paket yang Diterima }} \\
= & \frac{411.15338 \mathrm{~s}}{1656} \\
= & 0,24838 \mathrm{~ms}
\end{aligned}
$$

Hasil perhitungan jitter didapatkan nilai jitter sebesar 0,24853ms. Dari standard TIPHON nilai hasil jitter tersebut termasuk kategori bagus[6]. sehingga semakin kecil peluang terjadinya tumbukan antar paket menyebabkan semakin bagus pula nilai jitternya.

\section{KESIMPULAN}

Penerapan sistem Internet of Things (IoT) pada kandang jangkrik berhasil diterapkan untuk melakukan telecontrolling pada kandang jangkrik berdasarkan suhu, kelembapan dan waktu. Sistem juga dapat mengirim notifikasi output dan respon sesuai kondisi yang telah ditentukan dengan aplikasi telegram dan pengiriman data melewati website. Metode fuzzy sugeno berhasil diterapkan pada sistem untuk mengatur nilai optimal suhu kelembapan dan output yang akan digunakan untuk mengatur kondisi kandang jangkrik. Pengujian akurasi sensor dan Quality of Service (QoS) pada sistem telecontrolling mengunakan standar TIPHON, dan mendapatkan Hasil presentasi ketelitian untuk sensor DHT22 yaitu 98\% dan pada Qos throughput 3,112Kbps (buruk), packet loss sebesar 0\% (sangat baik), delay sebesar 248,38 (sedang) dan Jitter sebesar $0,24853 \mathrm{~ms}$ (bagus).

\section{REFERENSI}

[1] M. Tiar, P. Gunoto, M. Irsyam, and M. Si, “arduino UNO R3 telah dilengkapi dengan polyfuse yang dapat direset untuk melindungi port USB komputer / laptop dari," pp. $1-9$.

[2] Obiofarm, "BUDIDAYA TERNAK JANGKRIK (GRYLLUS MITRATUS BURM ),” wordpress, 2015.

[3] P. Widyaningrum, A. M. Fuah, and D. Sihombing, "Produktivitas Dua Jenis Jangkrik Lokal Gryillus testaceus Walk. dan Gryllus mitratus Burn. (Orthoptera: Gryllidae) yang Dibudayakan,” Ber. Biol. J. Ilmu-ilmu Hayati, vol. 5, no. 2, pp. 169-175, 2000,

[4] F. Puspasari, T. P. Satya, U. Y. Oktiawati, I. Fahrurrozi, and H. Prisyanti, "Analisis Akurasi Sistem sensor DHT22 berbasis Arduino terhadap Thermohygrometer Standar," J. Fis. dan Apl., vol. 16, no. 1, p. 40, 2020,

[5] D. Kusumawati and B. A. Wiryanto, "Perancangan Bel Sekolah Otomatis Menggunakan Mikrokontroler Avr Atmega 328 Dan Real Time Clock Ds3231," J. Elektron. Sist. Inf. dan Komput., vol. 4, no. 1, pp. 13-22, 2018.

[6] Aprianto Budiman, M. Ficky Duskarnaen, and
Hamidillah Ajie, “Analisis Quality of Service (Qos) Pada Jaringan Internet Smk Negeri 7 Jakarta," PINTER J. Pendidik. Tek. Inform. dan Komput., vol. 4, no. 2

[7] D. Priadi, "Measurement of Quality of Service (QoS) in File Sharing Applications with the Android-Based Client Server Method", Jaringan Telekomunikasi, vol. 6, no. 1, pp. 39-49, May 2018.

[8] Rieke Adriati Wijayanti, Ahmad Wilda Yulianto, Dianthy Marya, Muhammad Syirajuddin S., and Nurul Hidayati, "Antarmuka Mikrokontroller IoT (ESP32) Dengan USB Host max3421e", JASENS, vol. 1, no. 02, pp. 70-75, Dec. 2020.

[9] R. H. Yoga Perdana, N. Hidayati, A. W. Yulianto, V. Al Hadid Firdaus, N. N. Sari and D. Suprianto, "Jig Detection Using Scanning Method Base On Internet Of Things For Smart Learning Factory," 2020 IEEE International IOT, Electronics and Mechatronics Conference (IEMTRONICS), 2020, pp. 1-5.

[10] R. Agustina, D. Suprianto and R. Ariyanto, "Technology Acceptance Model Analysis of User Behavioral Intentions on IoT Smart Board Devices," 2021 1st Conference on Online Teaching for Mobile Education (OT4ME), 2021, pp. 89-92, doi: 10.1109/OT4ME53559.2021.9638937.

[11] Taufik, M., Rakhmania, A. E., \& Afnani, Y. N. (2020). Prepaid water meter card based on internet of things. In IOP Conference Series: Materials Science and Engineering (Vol. 732, No. 1, p. 012105). IOP Publishing.

[12] M. Taufik, H. Hudiono, A. E. Rakhmania, R. H. Y. Perdana, and A. S. Sari, "An Internet of Things Based Intercity Bus Management System for Smart City,” Int. J. Comput. Digit. Syst., vol. 10, no. 1, pp. 1219-1226, 2021

[13] A. Nurbaeti, M. Kusumawardani, and H. Darmono, "Design and Build a Coffee Bean Dryer Based on Internet Of Things", Jaringan Telekomunikasi, vol. 11, no. 2, pp. 74-80, Jun. 2021.

[14] M. Nas, Misnawati, Megha Rahmawaty Marsing, and Fadlia, "Prototipe Pemantauan Level Air Pada Bendungan Berbasis IOT", JASENS, vol. 1, no. 02, pp. 63-69, Dec. 2020.

[15] M. Mabe Parenreng, R. Damayanti, and A. Asriyadi, "Rancang Bangun Smart Home Berbasis Internet of Things", JASENS, vol. 1, no. 02, pp. 42 - 46, Dec. 2020.

[16] D. Suprianto, R. Agustina, and T. A. Izzuddin, “" Best Practice 'Pengembangan Aplikasi Internet of Things," 2021. 